Review

\title{
Increase Service Life for Rail Wheel Bearings-A Review of Grease Lubrication for This Application
}

\author{
Hannes Allmaier 1,2 (D)
}

Citation: Allmaier, H. Increase Service Life for Rail Wheel Bearings-A Review of Grease Lubrication for This Application. Lubricants 2022, 10, 36. https:/ / doi.org/10.3390/lubricants10030036

Received: 22 November 2021 Accepted: 9 February 2022 Published: 3 March 2022

Publisher's Note: MDPI stays neutral with regard to jurisdictional claims in published maps and institutional affiliations.

Copyright: (C) 2022 by the author. Licensee MDPI, Basel, Switzerland. This article is an open access article distributed under the terms and conditions of the Creative Commons Attribution (CC BY) license (https:// creativecommons.org/licenses/by/ $4.0 /)$.
1 Virtual Vehicle Research GmbH, Inffeldgasse 21A, 8010 Graz, Austria; hannes.allmaier@v2c2.at; Tel.: +43-316-873-4006

2 AC2T Research GmbH, Viktor-Kaplan-Straße 2/C, 2700 Wiener Neustadt, Austria

\begin{abstract}
Billions of rolling bearings (RB) are in use today in a broad and diverse range of applications. In the mobility sector, RB help to reduce friction losses and increase efficiency. In rail applications, the rail wheel rolling bearing is a critical component, which requires a strict maintenance schedule. In this literature review, grease lubrication in RB is reviewed and potential ways to improve the service life of greases in RB are discussed with special emphasis on the application as rail wheel bearing. Understanding the discussed fundamental lubrication processes is the key to increase the service life of the rail wheel bearings and might provide a basis for future work that aims to make maintenance of these bearings condition-based (condition-based maintenance). This review is primarily intended for R\&D professionals from rail (and related) industry and others being interested in a rather brief, but fundamental, overview of this subject.
\end{abstract}

Keywords: grease; lubrication; rolling element bearings

\section{Introduction}

While oil-lubricated journal bearings can be described accurately by the Reynolds equation to the point that friction [1-4] and related properties such as wear [2,5] and bearing temperature can be predicted [6], RBs are considerably more complex. In contrast to the (usually) fixed journal in a journal bearing, which gives clearly defined kinematics of the involved bodies, the rolling elements might conduct a combined sliding and rolling motion (Similar to [7], which by itself is already difficult to tackle in simulation). In addition, grease is an inhomogeneous multiphase compound that cannot fully be described by the Reynolds equation. Further, the experimentally found film thicknesses for RBs are often smaller than $100 \mathrm{~nm}$ [8,9] — that is one magnitude smaller than comparable film thicknesses in journal bearings. Consequently, mixed lubrication is omnipresent which is highly nonlinear and depends fundamentally on surface properties [10].

Consequently, the present work focuses heavily on the review of experimental works; for an extensive discussion of the theoretical modeling of lubrication and other related aspects in rolling element bearings, the author refers to [11]. A number of grease life estimation models (usually derived from experimental data) have been developed in the past and a detailed overview is given in [12].

As there exist vast amounts of highly interesting literature on all aspects of rolling bearing lubrication, this review does not claim to be complete by any means. Instead, it tries to present a general picture citing papers that appear to be particularly relevant for the intended application in rail wheel bearings. The list of references cited shall not be considered complete but serves only as a starting point for further literature.

While a great amount of work focuses on the rolling contact fatigue [13], most bearings fail due to failed lubrication [14-16]. Specifically, in the rail sector, a strict service schedule is employed where the rail wheel bearings need to be regreased for this reason in defined intervals. With rail wheels today having a longer usable lifetime than the grease in the rail 
wheel rolling bearings, this is a motivation to improve grease life and, ideally, to match it to the rail wheel life to reduce service costs (private communication with a major OEM of the rail industry.). Therefore, topics such as grease composition, ball bearing lubrication (lubrication in the contact, grease replenishment, etc.), which are directly linked to lubrication, will be discussed in the following.

\section{Lubrication Fundamentals: Grease Composition and Bearing Lubrication}

\subsection{Grease Composition}

Several works indicate that for severe operating conditions with temperatures above $60-70{ }^{\circ} \mathrm{C}$, the grease becomes the service life limiting factor [17] for rolling bearings (RBs).

Greases used for the lubrication of rolling bearings are inhomogeneous multiphase compounds and consist generally of at least three components [12]:

- base oil

- $\quad$ thickener (matrix)

- $\quad$ additives

The base oil can be made of mineral oil, of synthetic oils, and of mixtures of these two. Mineral oils are generally cheaper to produce than synthetic base oils; they often have a rather short lubrication life, also due to their not so good oxidation stability. Some exhibit a high evaporation rate and excessive oil separation. Finally, mineral oils can vary significantly from production lot to lot depending on the crude oil used as feedstock [18].

Synthetic base oils can be made of esters, polyalphaolefins (PAO), silicones, perfluoropolyethers (PFPE), and others. From these, only the esters and PAOs are suitable for the intended railway application as the others either have poor load carrying capacity or other undesirable properties. Esters and PAOs also have a long lubrication life [16].

Polyalphaolefins (PAO) are widely used in lubrication greases and engine oils. These base oils commonly achieve good lubrication properties and can be used over a larger temperature range than mineral oil based greases. With the exception of low viscosity grades, they are compatible with most sealing materials. PAOs are fully miscible with mineral oils and esters and can be combined with a large range of additives [18].

Generally, ester-oil-based greases have excellent lubrication properties, are compatible with a wide range of additives, and can be used over a wide range of temperatures up to $150{ }^{\circ} \mathrm{C}$. Under high-temperature operation, they typically have a much longer lubrication life than PAO-based greases. Ester oils are commonly only available in low to medium viscosity grades and may be incompatible with some sealing materials [18].

Another class of greases are the urea greases that have at least one urea group (-NH-CO$\mathrm{NH}-$ ). Commonly, there exist diurea, triurea, and tetraurea greases, and the chemical flexibility in the number of urea groups allows to cover a large range of physical properties such as dropping point, consistency, and shear stability. In comparison to other soap-based greases, the urea greases have several advantages as superior heat resistance, oxidation stability, and longer service life at high temperatures. Their drawbacks are generally poor shear stability, poor rust prevention, and a tendency for thermohardening. However, there exist several fully formulated urea greases that claim to have overcome these limitations [19].

Perfluoropolyethers (PFPE)-based greases are not so commonly used for lubrication in RBs despite their good properties. They are normally thickened with polytetrafluoroethylene (PTFE), chemically inert, fire-resistant, and show a consistent performance over a large range of operating conditions. With their high viscosity index and high thermal and oxidative resistances, they can be used over a large range of temperatures [20] and have a low volatility. They have good lubricating properties due to the fact that PFPE generates iron fluoride in the contact zone, which has antiwear properties. However, under lightly loaded conditions, PFPEs generally show only marginal lubricity. Under heavily loaded (extreme pressure) conditions, these may be subject to catalytic breakdown in the presence of steel debris (e.g., from wear). PFPEs also may suffer degradation at temperatures above $200{ }^{\circ} \mathrm{C}$ in the presence of nonpassivated metals like aluminum or titanium alloys. In that case, the degradation is accompanied by the release of small amounts of gases, which 
are toxic and corrosive [21]. Only few compatible additives are known and experience with these appears to be limited. PFPEs are commonly compatible with sealing materials but are not miscible with mineral oils, PAOs, and esters. Furthermore, they have a high volume resistivity, which might be useful in railway applications [21]. Currently, they are particularly used in aerospace, spacecraft, and pharmaceutical applications, which are less price-sensitive applications $[18,20]$.

The thickener materials can be divided into organic and inorganic thickeners. Organic thickeners may or may not be soap-based, while inorganic thickeners are nonsoap-based. Simple soaps are formed by a reaction with alkali earth metals such as lithium or calcium. To obtain higher performance soaps (such as higher dropping point), a complexing agent is added to the soap thickener to convert it to a soap salt complex thickener.

Common thickeners are calcium soap, calcium complex soap, lithium-12hydroxystearate soap, lithium complex soap, and polyurea thickener. From these, in particular, lithium complex soap appears to be suitable for the intended railway application (excellent shear stability, good oxidation stability, good water resistance, and operational temperatures up to $170{ }^{\circ} \mathrm{C}$ ). In the case of PFPE as base oil, the thickener is PTFE, which has excellent oxidation stability, water resistance, and, notably, excellent sliding properties [18].

Commonly, the corresponding thickeners are chosen on the required operating temperatures of which lithium soaps generally cover the largest temperature range from $-20{ }^{\circ} \mathrm{C}$ to $+130^{\circ} \mathrm{C}$ [22]. As expected, greases used in rail applications such as the Kajo 085.30 or the FAG L225 employ lithium soap thickeners.

While there exist RBs that do not rely on grease but, e.g., are lubricated only with oil, most RBs are sealed for life and contain a grease. To achieve this thick consistency, a solid thickener is added to the base oil. These thickener fibers have a length of about 1 to $100 \mu \mathrm{m}$ and generally have a length to diameter ratio of 10 to 100; for scanning electron microscope pictures showing these inhomogeneous structures, see, e.g., [23].

The base oil is kept inside the thickener structure by a combination of van der Waals and capillary forces. Despite its appearance, grease consists to about $80-90 \%$ of base oil [23].

Furthermore, additive chemistry is used to provide further enhanced functionality such as protection against corrosion, wear, and grease oxidation. Despite that additive chemistry is understood to some extend for, e.g., engine oils (e.g., see the extensive literature on ZDDP film formation in oils, e.g., [24-26] and many more), the working mechanisms behind additives in greases are rather unclear and there are still many fundamental open questions, even for ZDDP [27]. Nevertheless, the efficiency of some extreme pressure additives containing phosphor and sulphur as they are used in API GL5 gear oils has been shown [28].

In addition, many known additives interact with the thickener due to their surface active properties. As most thickeners are polar as are the common additives, they interact, which often leads to a harmful/deteriorating effect on the thickener structure and also reduces the efficiency of many additives. Due to this interaction with the thickener, it is suspected that the additive efficiency may change with the aging of the grease [23].

In contrast to engine oil whose performance is largely described by its viscosity, lubricant grease significantly alters already at the begin of the bearing operation and might also contain a significant amount of air. This makes it a multiphase compound that cannot be fully described by simply accessible grease rheological properties.

Further, the rheological properties of grease are complicated to the fact that grease shows thixotropic and non-Newtonian behavior: thixotropic means that the grease properties depend on its stress history; the most popular substance showing this behavior is tomato ketchup. Mechanically working the grease lowers its viscosity, and this effect persists for a certain time after the mechanical shearing stopped. Once shearing ends, viscosity increases again during resolidification [23].

Non-Newtonian behavior: Creeplike behavior was observed for low shear rates until the yield strength has been reached; at high shear rates, the grease rheology approaches that of the base oil. Mechanical work changes the rheological behavior of grease significantly [23]. 
In terms of characterization, there exist a number of grease tests: the solidlike behavior, or resistance to flow, is traditionally characterized through the consistency (or penetration) measured using a cone penetrometer (ISO 2137, ASTM D217), which is translated into an NLGI consistency number [23], see Table 1.

Table 1. Overview of the NLGI consistency scheme [29].

\begin{tabular}{cccc}
\hline NLGI Number & Appearance & $\begin{array}{c}\text { ASTM Worked } \\
\text { Penetration } \\
\mathbf{( 1 / 1 0 ~} \mathbf{~ m m})\end{array}$ & Application \\
000 & Semifluid & $445-475$ & gear greases \\
00 & & $400-430$ & \\
0 & Soft & $355-385$ & greases for bearings \\
1 & Creamy & $310-340$ & \\
2 & & $265-295$ & block greases \\
4 & & $220-250$ & $175-205$ \\
5 & Soaplike & $130-160$ & 85-115 \\
6
\end{tabular}

Finally, it is interesting to note that the properties of greases, in particular for metallic soap-based greases, depend not only on their actual composition, but also, and to nearly the same extent, on the way in which the thickeners are prepared and dispersed [29].

\subsection{Lubrication in RBs}

Even at present, the exact mechanisms behind RB lubrication are not completely understood. The current state of the art is briefly presented in the following; for a considerably more in-depth discussion, the author refers, e.g., to [30].

A new RB contains only fresh grease that is present also in an homogeneous form within the bearing. However, this initial situation is not representative for the actual working conditions as it does not last for long. It was shown in several experimental investigations [9] that the grease properties and the film thickness [31] undergoes large changes already during run-in of the new bearing.

Already at the beginning of the bearing operation, most of the grease is pushed away from the raceway to the seals. This is-in part-intended as this surplus grease acts an additional seal. However, this behavior also has the consequence that only a small amount of grease remains on the raceway for lubrication. Due to the grease being pushed out of the raceway caused by the rolling elements, generally, too little grease remains in the actual contact. Therefore, the lubrication conditions are starved and the bearing lubrication strongly depends on the ability of the bearing to reflow grease (or, more specifically, some of its low viscosity components) back into the contact (more on that in Section 2.3). It was shown that mechanical shear degradation during operation is able to improve this process [31].

Due to these processes, the grease is usually in different condition in different parts of the RB. Notably, differences arise for the grease on the shields, the cage pockets and the actual contact at the raceway [31,32].

\subsubsection{Basic Influence of Grease Properties on RB Lubrication}

It is commonly known that thick grease (grease with high viscosity at ambient pressure) causes high power losses due to churning in the bearing and is, therefore, not well suited for high speeds.

However, it as also found experimentally that a high grease viscosity earlier leads to starved lubrication conditions in the contact [9]. This can be explained by the slower lubricant replenishment of higher viscosity greases [33,34]. Therefore, starved lubrication conditions not only occur as expected for high speed working conditions but may also occur at low temperatures due to the corresponding high grease viscosity [33]. 
As can be seen in Figure 1, the film thickness in the contact (for speeds larger than $0.1 \mathrm{~m} / \mathrm{s}$ ) is actually higher for the lower base oil viscosity.

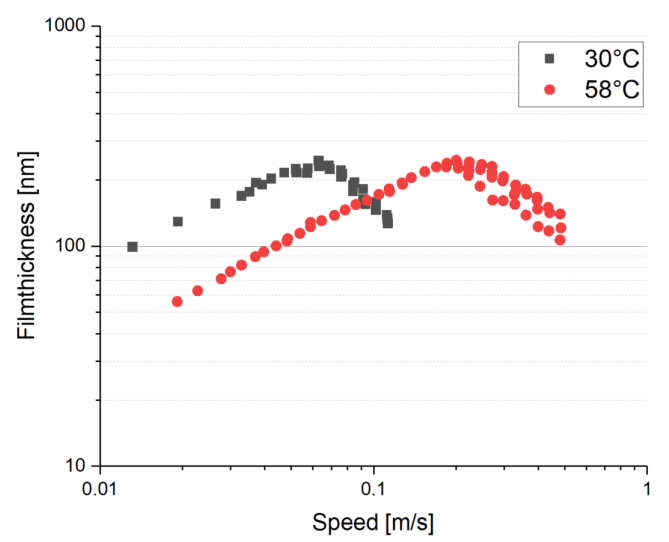

Figure 1. Influence of the base oil viscosity on the film thickness in the contact for different rolling speeds (data from [35]). Due to the strong temperature dependence of the base oil, the higher temperature $\left(58^{\circ} \mathrm{C}\right)$ corresponds to a much lower viscosity than the lower temperature case $\left(30^{\circ} \mathrm{C}\right)$.

\subsubsection{Lubrication in the Contact}

Lubrication in the contact was investigated in detail in [9] using a ball on disc test-rig. At the start of the test, the contact is lubricated by an inhomogeneous film containing base oil and thickener (see left of Figure 2). However, it was shown that already after one minute of operation (at a speed of $0.1 \mathrm{~m} / \mathrm{s}$ ) l, most of the grease is pushed outside the contact and only a 200-300 nm thick film remains in the contact (see right of Figure 2).
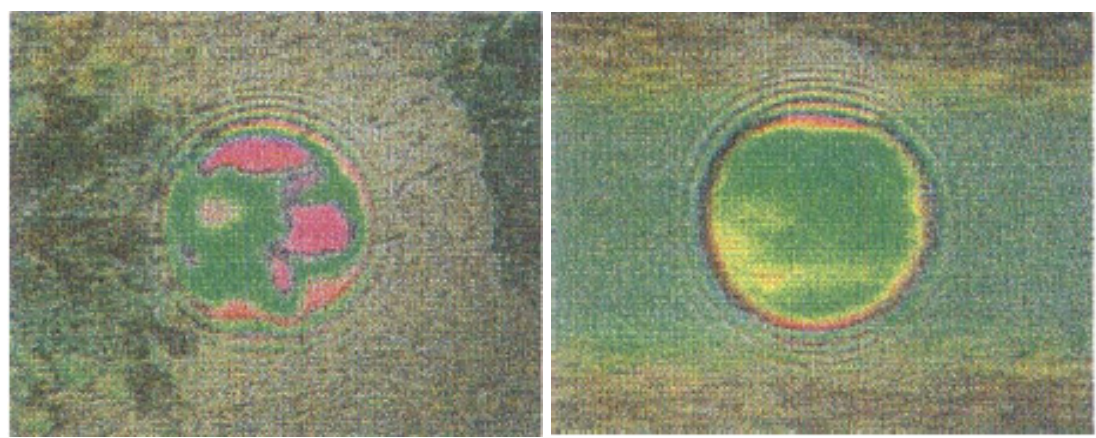

Figure 2. Film thicknesses in the rolling contact for different running times: the left picture shows the inhomogeneous film consisting of base oil and thickener right at the start of the test. The right picture was taken after only one minute of operation (pictures reproduced from [9]).

With increasing operating times, the thickener in the contact is repeatedly overrolled by the rolling elements. This repeated mechanical working and the associated shear and thermal stress mechanically destroy the thickener on the raceway [36] and change significantly its rheological properties [37] like its viscosity. This process is irreversible due to the breakdown of the grease matrix and causes a viscosity loss of the lubricant in this part of the bearing. In [9], it was found that after 20 min operating time, the thickener was broken down to give a fairly constant film of about $20 \mathrm{~nm}$. Furthermore, it was found that at the side of the contacts localized EHD film formation occurs due to improved lubricant flow (free base oil). These findings can be seen in Figure 3 where the film thickness is shown for the rolling case and after rolling has stopped (static case). The depicted results show that the actual load carrying in the middle of the contact is provided by a solid deposited layer of thickener with some base oil. In more detail, the layer is composed of small particles with associated droplets of fluid. To the sides of the contact, this is further supported by hydrodynamic film formation [9] in the rolling case. Depending on rotational speed, the 
solid deposited layer can reach thicknesses between $20-80 \mathrm{~nm}$ and is most effective for low speeds [38]. As the thickener is involved in bearing lubrication, it is not surprising that thickeners affect contact replenishment [39] and grease life [12]. Contact replenishment will be discussed in the next section.

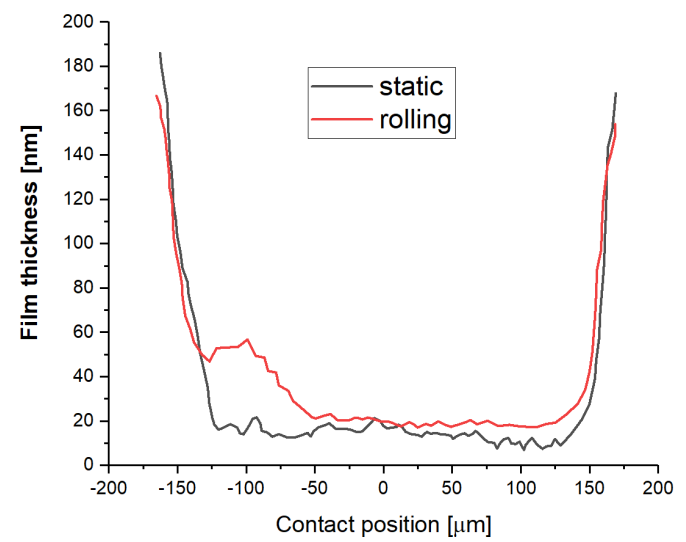

Figure 3. Film thicknesses in the rolling contact during rolling and after rolling stopped (static case). It can be seen that in the middle of the contact $(0 \mu \mathrm{m})$ the film thickness is unchanged, while it increases at the sides during rolling (data from [9]).

Similar results were found in a railway field test [40], where the main mechanical degradation of the grease occurred within the first $25,000 \mathrm{~km}$. After this traveling distance, the grease consistency remained largely constant.

Finally, it was also found that the bearing materials might play a bigger role than anticipated. Cann [41] invested grease degradation in RBs and found an ester contamination originating from the seal after $50 \mathrm{~h}$ operating time, which further increased with working time. This ester structure is similar to the product that forms during thermal degradation of the grease and was found on the raceway.

\subsection{Contact Grease Replenishment}

Basically, two mechanisms are under discussion to allow grease to get back into the contact:

- $\quad$ side flow of base oil due to capillary action

- intermittent flow of overrolled grease

Both processes need to be considered for grease replenishment and are shown schematically in Figure 4; however, it is interesting to note that both processes are facilitated by shear degradation of the grease [31] and increased operating temperatures.

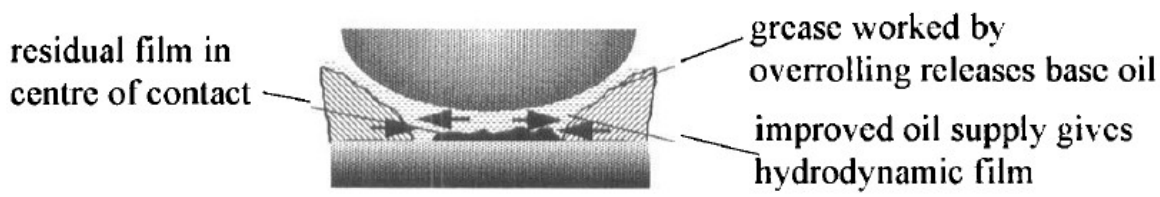

Figure 4. Schematical overview of the grease lubrication in the contact (reproduced from [9]).

In particular, on ball-on-disc machines the capillary action was observed in several works [34]. The process of capillary action indicates that surface properties of the raceway play an important role as they potentially could be used to improve the capillary action.

Grease replenishment is the major factors in bearing lubrication and is, unfortunately, generally worse for high aspect ratio contacts (cylinder roller bearings, etc.) as the distance from the sides to the actual contact is larger [9,33]. 
One of the possibilities to improve these processes for better grease replenishment into the contact is to use suitable bearing cages [42], see Figure 5.

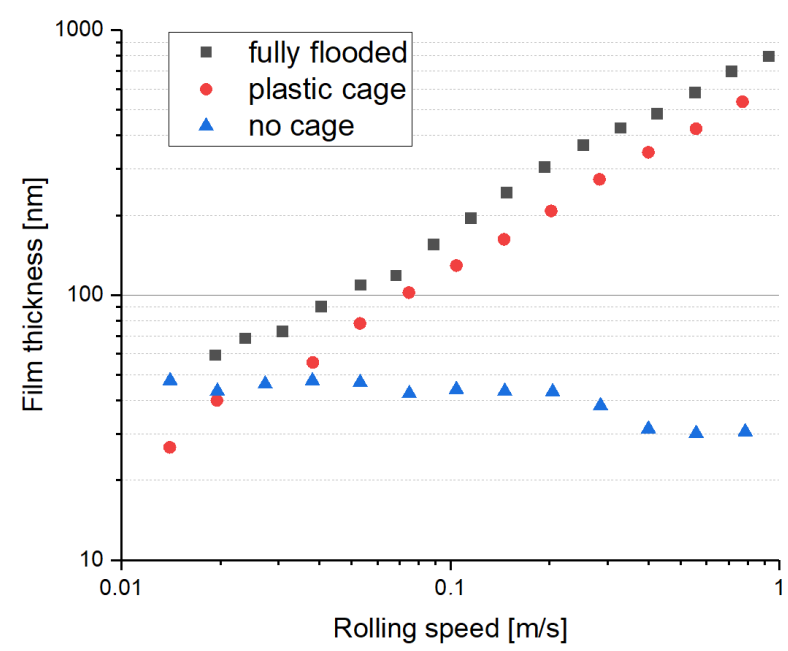

Figure 5. Influence of the cage on the film thickness in the contact for different rolling speeds (data from [35]). For reference, fully flooded conditions are shown.

It is interesting to note that the presence of a bearing cage leads to worse lubrication for bearings that were lubricated only by the base oil, the exact opposite behavior was found for grease-lubricated bearings [33]. In case of lubrication only with base oil, the cage acts as scraper and actually removes lubricant from the contact. This effect can be seen in measurements of the film thickness for bearings with different bearing cage clearances (see Figure 6).

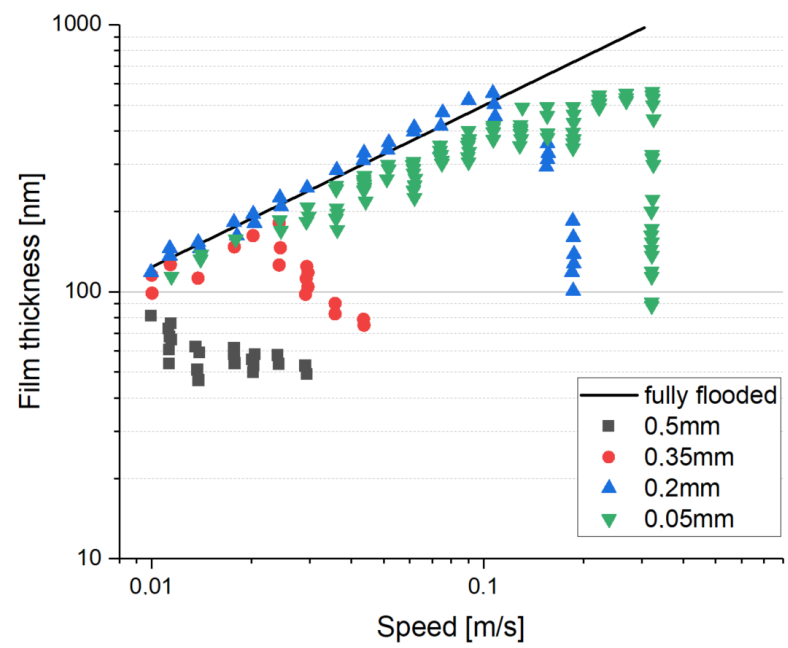

Figure 6. Influence of the cage on the film thickness of a grease lubricated contact for different rolling speeds and for different cage clearances. The straight line denotes fully flooded lubrication as reference; as illustrated, decreasing cage clearance has a strong effect on film thickness (data from [33]).

On the other hand, for grease-lubricated RBs, the cage can be used to improve contact lubrication. In the case of grease, the bearing cage acts as a reservoir that helps to promote grease back into the track. This can also be seen in film thickness measurements for different clearances (see Figure 6), where reduced clearances tend to cause larger film thicknesses. 
Not only does the bearing cage help to push the grease back into the track, it is further probable that the mechanical shearing of the grease due to the cage further decreases the grease viscosity, which again promotes the lubricant replenishment [33].

To summarize, the lubricant supply appears to be governed by the breakdown of the grease close to the track by repeated overrolling with the rolling element. This indicates that the grease behavior (grease structural breakdown) at relatively low shear stress levels to the side of the contact is of crucial importance for contact grease replenishment. This is also further supported by [43], that investigated the influence of the mechanical degradation on the film thickness and lubricant replenishment. It is shown that continued mechanical working of the grease lowers the yield stress of the grease significantly, as shown in Figure 7.

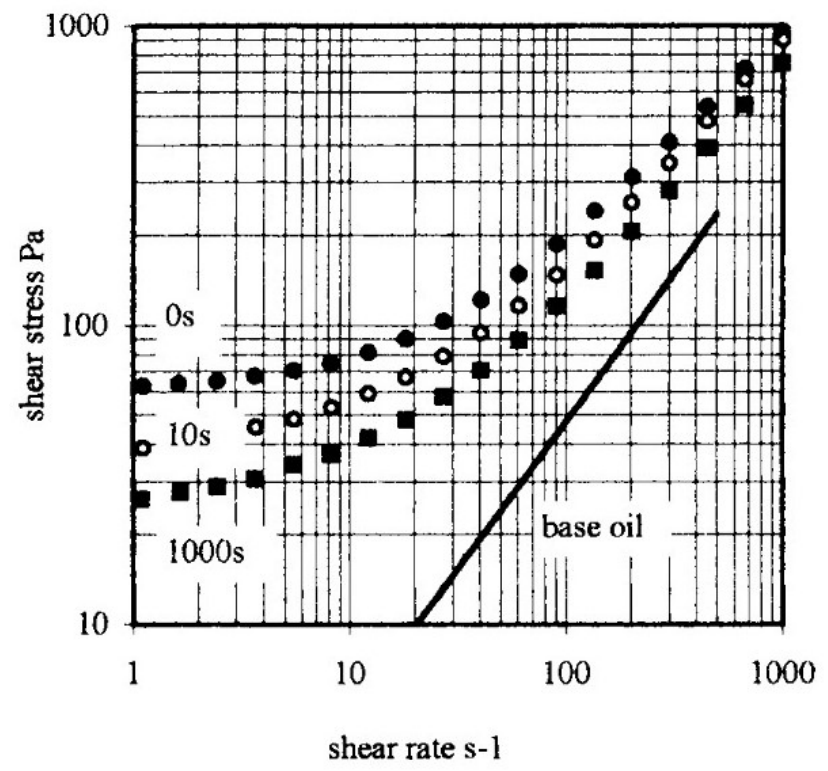

Figure 7. Shear stress measured for grease B from Figure 8 after different periods of mechanical working (after $0 \mathrm{~s}, 10 \mathrm{~s}, 1000 \mathrm{~s}$ working the grease at shear rate of $1000 \frac{1}{\mathrm{~s}}$ (reproduced from [43]). For comparison, the shear stress of the base oil is shown.

The lowering of the yield stress has important consequences for the RB lubrication. During the first rotations of a new bearing, the grease is repeatedly pushed outside the contact. Lubricant starvation occurs as the grease does not flow back by itself due to the required yield stress. As consequence, the film thickness in the contact declines constantly until the grease close to the contact is sufficiently degraded and its yield stress sufficiently lowered. When the yield stress decreased sufficiently, base oil is freed and flows back into the contact (supply recovery); this is shown in Figure 8.

As the grease close to the actual contact suffers this mechanical working during operation, it is indicated that this process promotes grease replenishment back into the contact. In the mentioned work, a relationship between the initial shear stress of three different greases and the shear rate and time-dependent shear stress was developed. Using this relation, it is predicted $[43,44]$ that the grease with the lowest initial yield stress (of the three investigated) resulted in the quickest supply recovery (denoted as grease B in Figure 8) [43]. These results are supported by measurements of the film thickness for these three greases, see Figure 9. 


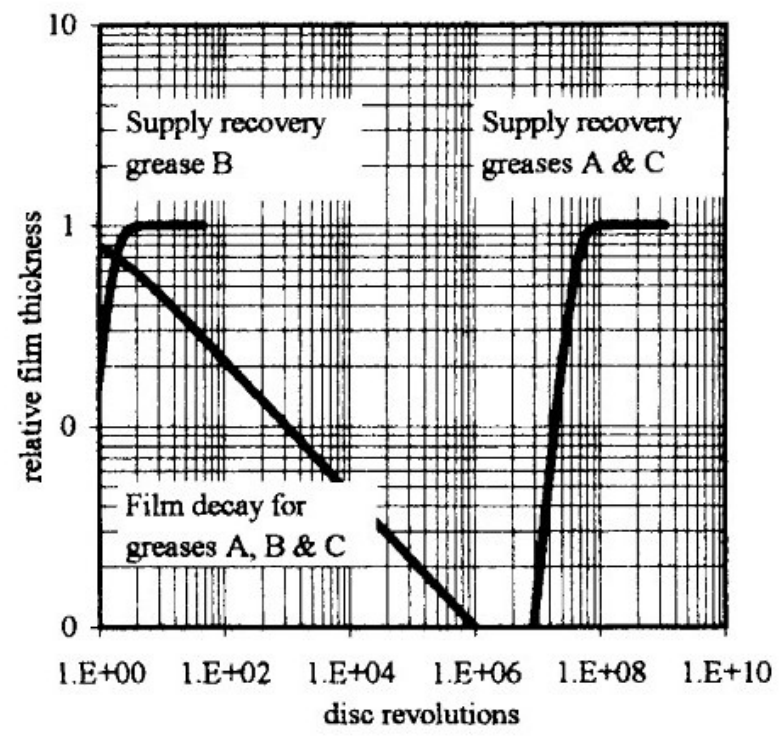

Figure 8. Plot of the calculated relative film thickness over time (number of disc revolutions in a ball on disc test-rig) for three different greases (reproduced from [43]).

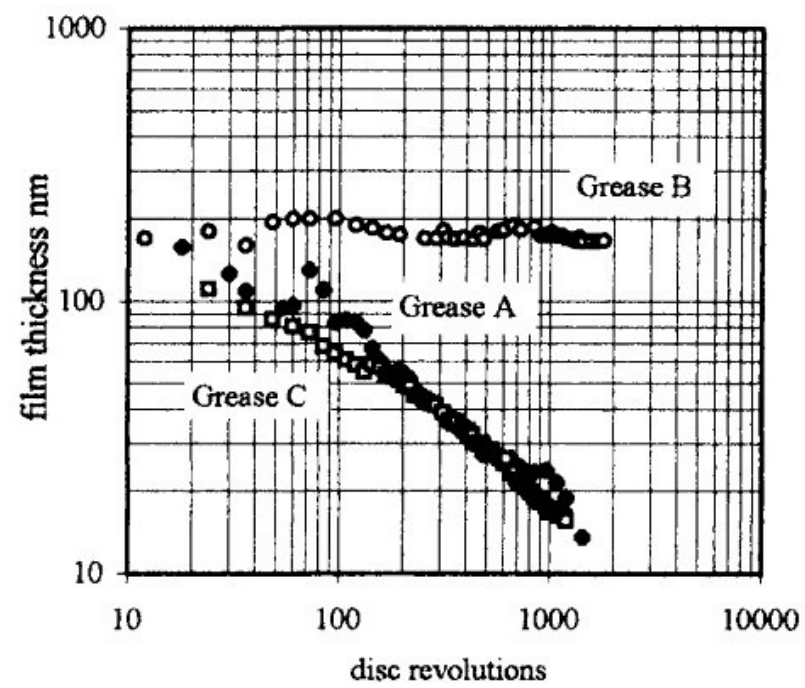

Figure 9. Measured film thicknesses for the same three different greases as in Figure 8 (reproduced from [43]).

Finally, it was shown by [32] that grease replenishment can be different for similar RBs that, however, employ different cage designs. While the asymmetrical plastic cage of the 6204 deep groove ball bearing of the R2F test promotes grease replenishment, the symmetrical steel cage of the 6305 deep groove ball bearing of the R0F test apparently does not promote the available grease for replenishment well. While in the former case, also in the cage pockets, low-viscosity mobile lubricant is found, such lubricant is found in the R0F-test only in the middle of the racetrack although sufficient grease was still present on the shields [32].

However, changes directly to the RB are not intended, as this would lead to bearings optimized for this specific application and a loss of the usability of many different bearings from different manufacturers.

Alternatively, an interesting work conducted from the Japanese railway research institute in collaboration with Toshiba [45] shows that optimizing the grease pockets (volume below the bearing covers) around the RB can be optimized such that the grease service life 
is significantly prolonged. However, in the mentioned work, the wheel bearings were not investigated, but the ball and rolling bearings of the traction motors were investigated (see Figure 10).
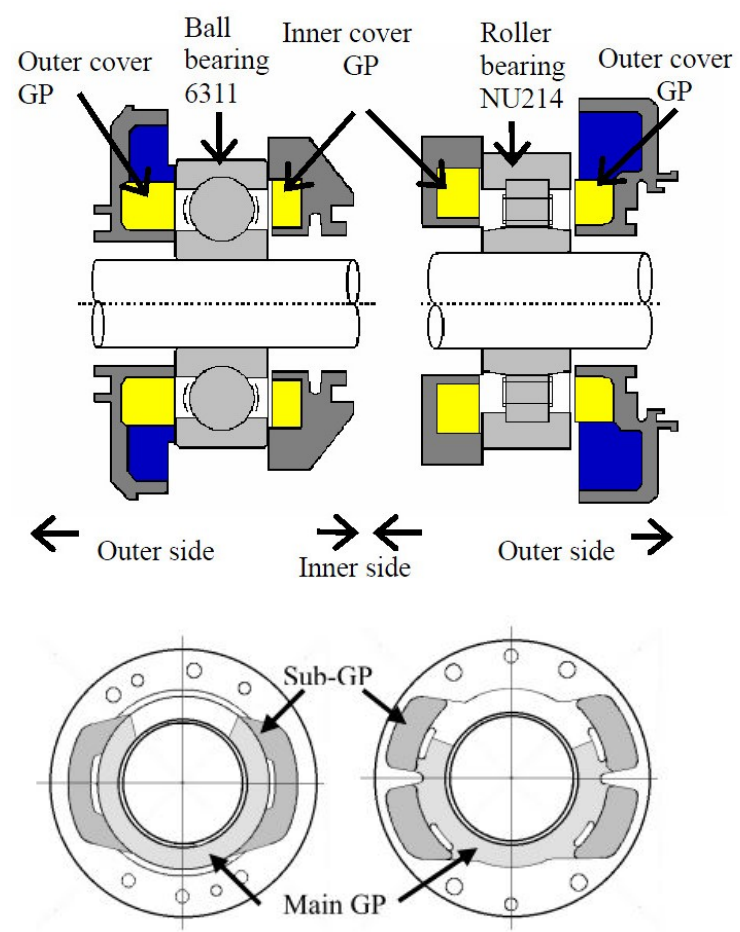

(A) Conventional type
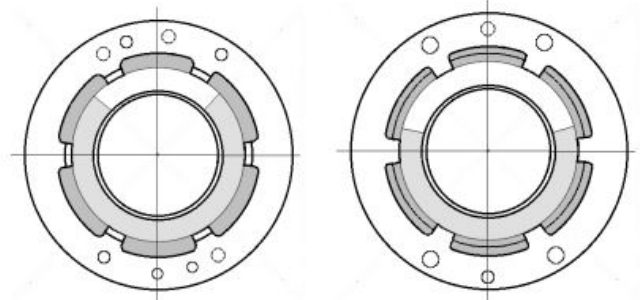

(B) Improved models \#1
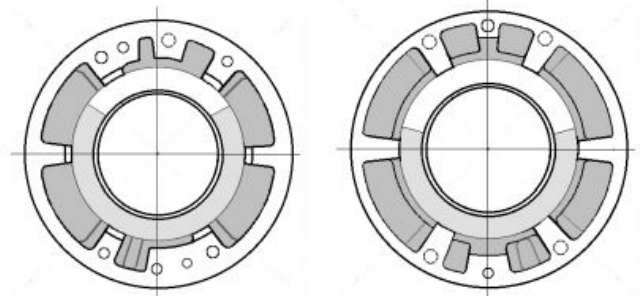

(C) Improved models \#2

Figure 10. Rolling element bearings of the railway traction motor as investigated by Hibino et al. [45]. The lower figure denotes the position of the grease pockets GP. (reproduced from [45]).

Increased running times of up to 3.6 Mio $\mathrm{km}$ in comparison to the previous 2.6 Mio $\mathrm{km}$ could be obtained for the rolling bearings (even more for the ball bearings) by changes to the grease pockets to promote grease replenishment (see Figure 11). 


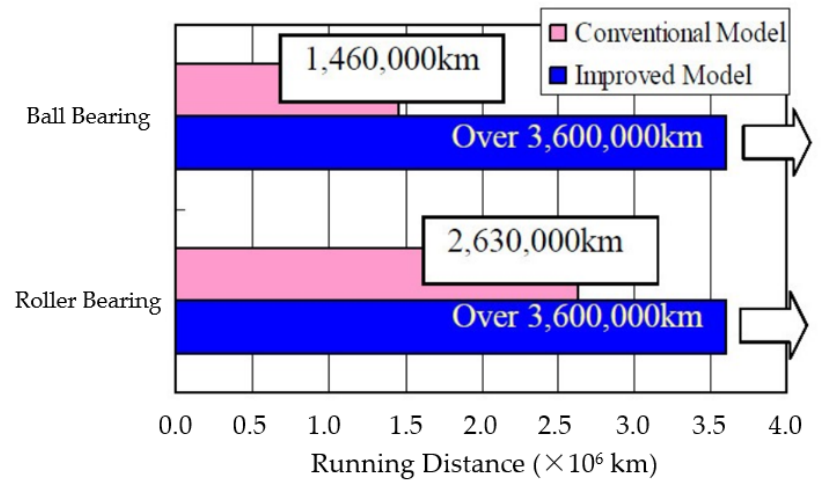

Figure 11. Obtained prolongation of the grease service life for standard (conventional) and improved grease pockets (reproduced from [45]).

The general finding of [45] was that it is advantageous to enclose as much grease as possible into the grease pockets. Refilling the bearing would be consequently also advantageous but may cause problems with the already filled volume. Furthermore, not only does the enclosed volume of grease in the grease pockets itself matter, but their shape also matters. However, this leads to higher bearing temperatures due to increased churning losses and needs to be taken into account. In the mentioned work, the temperature rise in the bearing was acceptable as the cooling during normal operation was sufficient to cope with the additional heat.

\subsection{Grease Induced RB Failure}

When a lubrication failure occurs in RBs, the mechanism behind the film generation failed, and this may have one or more of the following causes:

- Insufficient lubricant is available

- Failure due to grease degradation

Insufficient lubricant can be either the result of base oil evaporation, which means that base oil is essentially lost for lubrication. It might alternatively also mean that too little grease replenishment occurs in the RB, so while there actually might be sufficient grease in the bearing, it cannot be effectively used. These two processes also can interact, as, e.g., an increased base oil viscosity resulting from oxidation ha worse grease replenishment properties; the same is true if evaporation leads to a significant loss of base oil [32]. Generally, it has been observed that the amount of grease in the RB decreases with increased running time and increased severity of the operating conditions [32].

\subsubsection{Grease Degradation in Bearings}

To assess the reasons for bearing failure due to insufficient lubrication, the degradation of the grease plays a key role.

Mechanical working of the grease during operation, which leads to shear degradation of the grease thickener and was shown to be even able to improve lubrication [31], was already mentioned previously. Major progress was made in the last years in particular by Zhou et al. [46-48] to better understand this phenomenon. Notably, a master curve was presented that describes yield stress as a function of imposed energy; this master curve is capable to describe the mechanical aging process for grease in some parts of a roller bearing [47] and provides the basis for developing a remaining grease life model within certain limits [47].

Commonly, it is accepted that the operating temperature is the most significant factor that reduces grease life. It can be quite conveniently measured and can serve as a parameter for condition-based maintenance in railway applications [49].

Temperature-induced oxidation is a key process in the degradation of the grease. The oxidation rate doubles with each temperature increase of $10^{\circ} \mathrm{C}$ for common hydrocarbon- 
based lubricants [50]. Oxidation not only affects the lubrication properties of the base oil and the thickener but it is also accompanied (at least at high temperatures) with increased evaporation. Oxidation leads to increased volatility and consequent weight loss of the grease as can be seen in Figure 12.

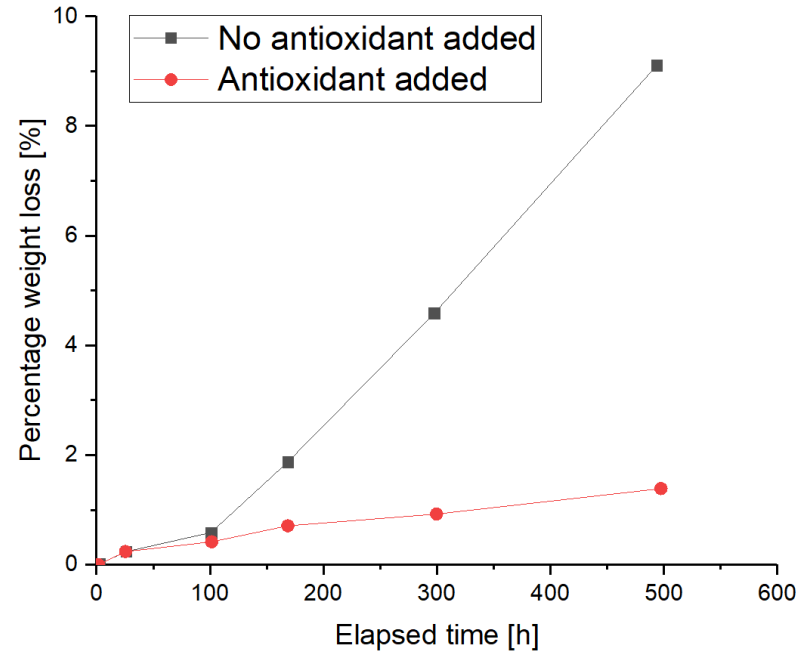

Figure 12. Base oil weight loss for an ester oil due to evaporation at a temperature of $120^{\circ} \mathrm{C}$ with and without antioxidant additives (data from [51]).

It was shown [32] that grease degradation due to oxidation in bearings is a complex process that depends on a large number of factors for a given bearing. Basically, this kind of grease degradation can be separated in thickener and base oil degradation. As both ingredients play a role in the lubrication process (see Section 2.2.2), both are discussed in the following.

As was noted earlier, the condition of the grease is different and depends on the position in the RB; notably, the grease on the shield, in the cage pockets, and on the actual raceway are different; therefore, they are discussed separately.

Shield lubricant: In short-term tests ( $40 \mathrm{~h}$ running time) the grease on the side shields is almost identical to fresh grease. However, the thickener concentration increases with increased running time due to base oil evaporation. Depending on the cage geometry and actual working condition, the grease is not symmetrically distributed on the left and right shields and also degrades differently [32,41]. Oxidation of the base oil is the main degradation mechanism, and even after failure, there is no severe thickener degradation. This is in contrast to the severe oxidation of the thickener on the raceway and suggests that the oxidation of the thickener is accelerated on the raceway for some reason. This reason could either be the higher temperatures, the occurrence of mechanical shearing, or the presence of metallic debris [32].

Cage pocket lubricant: In the first hours of operation $(40 \mathrm{~h})$, the grease in the cage pocket is similar to fresh grease but with an increased thickener concentration. After longer running times $(240 \mathrm{~h})$, the grease in the cage pockets is no longer homogeneous; it varies from grease that is similar to fresh grease (albeit with increased thickener concentration) to grease where mostly the base oil is heavily oxidized. The latter is only fluid at the elevated bearing operation temperatures and forms deposits when the bearing is stopped. As this degraded grease also suffers heavy mechanical degradation due to shearing, it represents the active lubricant in the cage pockets. Summarizing, the active lubricant in the cage pockets is heavily degraded lubricant that is both heavily oxidized and mechanically degraded and contains a high proportion of thickener [32].

Raceway lubricant: Usually, the raceway films are transparent with isolated areas of thicker film; in short-term tests $(40 \mathrm{~h}$ ), it was found that the lubricating films on the raceway contained thickener and base oil in similar proportions as fresh grease. After longer running 
times $(240 \mathrm{~h})$, the lubricant on the raceway formed a thin transparent film with transversal ridges of darker material. These ridges have a much higher thickener content, about $25 \%$ more than fresh grease. It was also found that the amount of thickener found on the raceway depends on the rotational speed of the bearing. For higher speeds, a lower amount of thickener was found, which led to the assumption that at higher speeds, the thickener is either ejected from the track or more severe shear degraded [32]. Severe chemical degradation took place as oxidized thickener and oxidized base oil was found on the raceway.

Comparing failed and nonfailed RB, it is necessary to distinguish between short-term failure, which originates in poor boundary lubrication or cage failure, and long-term failure. For the long-term failure, which is of particular interest, it was found that in both cases (failed and nonfailed RB) severely oxidized base oil is found on the raceway and the cage pockets. It appears that the oxidation of the base oil, therefore, determines the absolute grease life [32]. Some oxidation of the thickener was also present, but this is ascribed to the presence of metallic debris, which is known to accelerate thickener oxidation [32].

Conclusions: As the grease in the cage pockets and on the raceway suffers far more extensive oxidation than the shield grease, the condition of the shield grease is not suitable as guide for the degradation of the lubricant in the bearing. The lubricant in the cage pockets is inhomogeneous; the grease actively involved in the cage lubrication is both chemically and mechanically heavily degraded. For the raceway, it was found that it is not homogeneous and consists of base oil and thickener and their oxidized forms.

It is interesting to compare these results to the findings of a railway field test [40]. In the field test, no oxidation at all was found after $25,000 \mathrm{~km}$ and $57,000 \mathrm{~km}$. Unfortunately, oxidation tests were not carried out after more prolonged traveling distances. However, as the railway field test was conducted in a cold climate with an average summer temperature of $15^{\circ} \mathrm{C}$, this might be attributed to the correspondingly low bearing temperatures. The bearing temperatures in test did not exceed $65^{\circ}$, which is significantly below the $93{ }^{\circ} \mathrm{C}$ threshold that is typically denoted as begin of the main oxidation process. Below this threshold temperatures, oxidation is slow and inhibitors are effective [40]. The bearing temperatures measured (Data provided by a major rail OEM to the author.) on a rail wheel bearing in an EN 12082 endurance test (The EN 12082 test is a performance test for axle boxes in railway applications, which shall represent a traveling distance of more than $500,000 \mathrm{~km}$.) reach a maximum of less than $90^{\circ} \mathrm{C}$ for an ambient temperature of $20{ }^{\circ} \mathrm{C}$, which suggest that oxidation-at least in summer-might not be dominant but still be relevant for this application.

Finally, as grease degradation causes increased wear of the rolling elements, this wear not only causes increased operating temperature of the bearing but also yields wear debris in the grease [15]. As the wear debris stays within the bearing, it is typically rolled over many times, which can lead to further damage to the rolling elements, as well as to lubricant degradation. It was also found that wear debris can catalyze the grease oxidation process [52,53]. Consequently, the monitoring of wear debris in the grease can be used to determine the state of health of the grease $[15,54]$.

\subsection{Role of Additives and Base Oil Quality}

While the role of additives is at present still not known in detail, there are a number of works indicating that suitably chosen additives significantly prolong the grease service life. As oxidation is an important process in grease degradation (as described in Section 2.4.1), oxidation inhibitors help to improve grease service life [32,55]. For one, case improvements of $30-80 \%$ were found, and in another work [32], the comprehensive additive package (The additive package contained antiwear and antioxidant additives, rust inhibitor, friction modifier, extreme pressure additives, and a copper passivator. In total, the additive package constituted 4.6 weight- $\%$ of the grease.) prolonged the grease service life between $100-700 \%$, in particular, for high speed applications. This is also seen in an earlier work [55] on highspeed bearings (7008 angular contact ball bearings at a rotational speed of $24,000 \frac{1}{\mathrm{~min}}$ ), where 
both increased thickener concentration and added antioxidant additives helped to prolong the grease service life. In a railway field test [40] (More details on the railway field test can be found in the following paragraphs on the base oil influence.), increased thickener concentration ( 8 weight-\% vs. 12 weight-\%) prolonged grease service life significantly. Adding antioxidants improved in one case the grease service life from $1000 \mathrm{~h}$ to $1600 \mathrm{~h}$ and in combination with an increased thickener concentration the grease service life was improved from $1700 \mathrm{~h}$ to more than $3500 \mathrm{~h}$ [55] (see also Figure 13).

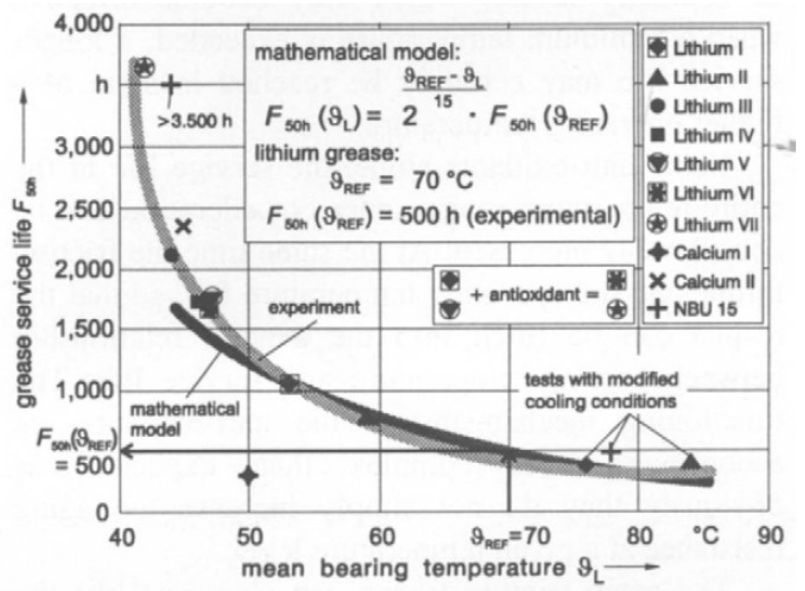

Figure 13. Measured service lifes for different greases: as denoted, greases VI and VII are identical to greases I and V but include antioxidant additives (reproduced from [55]).

It is interesting to note that extreme pressure additives can increase grease life. These reduce the severity of the contact and, therefore, lead to both lower operating temperatures and less metallic debris, which accelerates thickener oxidation [32].

Base oil: The quality of the base oil has a significant effect on grease service life. Without additives, it was shown for one case [55] that synthetic PAO base oil has the longest service life for the base oils investigated (mineral oil, PAO, ester). It is not fully clear which properties of PAO determine that PAO is better suited for RB lubrication in comparison to mineral oils. From experimental works [40,55], the better lubrication is not linked to a higher base oil viscosity. From the findings of [32], indeed, the grease viscosity at low shear rates is expected to play an important role, but this property was not investigated in $[40,55]$.

In field tests conducted with railway ore wagons [40], nine different, fully formulated greases recommended for this application were tested and compared in terms of their performance. These nine different greases were used to lubricated RB of ore wagons for a traveling distance of about 300,000 km. In the cited work, four greases were found to deliver satisfactory performance in terms of wear protection, consistency, rust, and friction. From these four greases, only one consisted of synthetic PAO base oil, while the remaining three were composed of mineral base oil. While the NLGI consistency was quite similar for all four greases (1.5-2), the base oil viscosity at $40{ }^{\circ} \mathrm{C}$ was remarkably different, ranging from $100 \frac{\mathrm{mm}^{2}}{\mathrm{~s}}$ to $460 \frac{\mathrm{mm}^{2}}{\mathrm{~s}}$. The thickener type was not consistently the same but included lithium complex as well as Li-12-Oh.

Among the other five greases that did not fulfill the requirements, there were also two greases made of synthetic base oil (one PAO-based, one ester-based). While these two offer the same good mechanical stability and low bearing temperatures that the four suitable greases also exhibit, these caused either increased bearing wear or increased bearing damage due to electrical currents. A third grease contained synthetic PAO base oil, but it was combined with calcium thickener, and this combination already failed early in the field test.

It was also found in [55] that fully formulated greases can reach significantly prolonged service lives than simple combinations of base oil and antioxidant additives. 


\section{Potential Ways to Improve Bearing Service Life by Enhancing Lubrication}

Figure 14 summarizes the various relevant factors influencing grease service life for the intended application. Given the working conditions and used bearing types, it appears that a number of promising possibilities remain to prolong grease service life significantly.

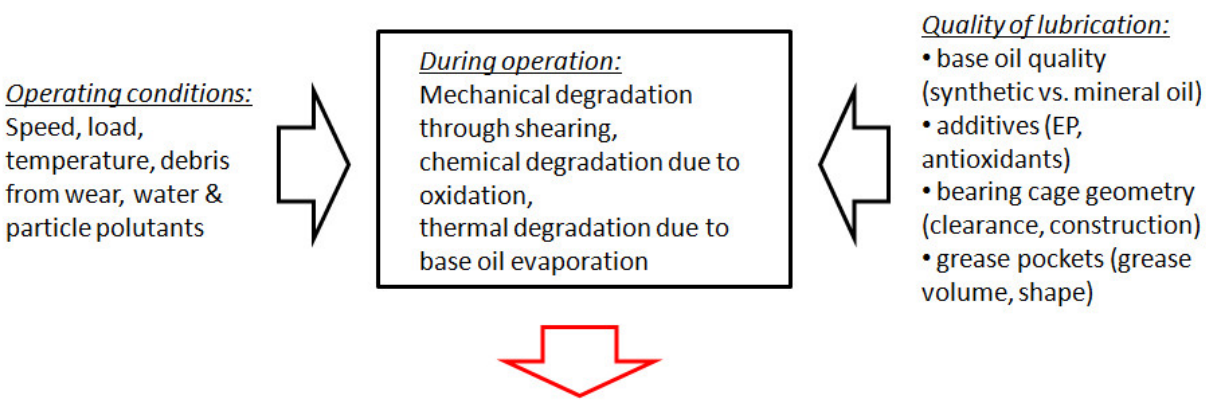

obtainable grease service life

Figure 14. Overview of the processes relevant for the intended application related to grease service life: for given operating conditions and without resorting to special RBs optimized for this application, the optimization of the grease and of the bearing housing (grease pockets) offer possibilities to prolong grease service life.

Optimally, one would start directly at the heart of the lubrication problem and investigate means to directly improve contact lubrication and grease replenishment back into the contact. Of particular interest in this regard is the construction of the bearing cage. The choice of geometry, clearance, and material dictates whether the combination harms bearing lubrication by scraping lubricant from the rolling elements and further supports the aging of the grease by releasing similar molecules into the grease or, alternatively, improves RB lubrication by supporting lubricant replenishment.

Despite the fact that such bearing optimizations are not the intended methods, for other reasons, a number of promising levers remain. Notably, the development of more refined grease pockets in the bearing housing has been proved to be able to obtain much longer grease service lives. However, the corresponding increased heating in the bearing needs to be kept in mind and a balance needs to be found. A compromise in this regard appears to be the possibility of lubricant refills; however, these come with their own drawbacks.

Also an investigation of the thermal conditions in the bearing housing (e.g., by means of simulation) would provide valuable information on the actual occurring temperatures in the RB that can be used consequently to investigate the benefits of increased cooling or other means of thermal management.

Aside from such constructive optimizations literature shows that there is still room left for significant optimizations related to the choice of the grease itself. The experimental data in the literature clearly shows that there are a large range of superior greases available that offer significantly increased performance levels in comparison to common Li-based greases. Therefore, it appears promising to investigate the suitability of such greases for rail road applications that consist of more recently developed base oil and thickener materials like polyurea or PFPE.

From a theory point of view, it would be an interesting approach to relate grease properties to lubrication performance was discussed in Section 2.3. The discussed approach of relating the initial yield stress of the grease to its mechanical degradation and film thickness could be investigated and used consequently to find better performing greases even more efficiently.

Summarizing, it appears that the the combination of constructive optimizations of the bearing housing (optimized grease pockets and thermal conditions) in combination 
with choosing a higher-performing grease might be a promising approach to significantly prolonged grease service life for rail wheel bearings.

Funding: This project has received funding from the Shift2Rail Joint Undertaking under the European Union's Horizon 2020 research and innovation program under grant agreement No 777629. In Austria, the project was also funded by the program "Mobilität der Zukunft" of the Austrian Federal Ministry for Climate Action (BMK) as well as by the Province Styria (Land Steiermark) and the Styrian Business Promotion Agency (SFG). The publication was written at Virtual Vehicle Research GmbH in Graz and partially funded within the COMET K2 Competence Centers for Excellent Technologies from the Austrian Federal Ministry for Climate Action (BMK), the Austrian Federal Ministry for Digital and Economic Affairs (BMDW), the Province of Styria (Dept. 12) and the Styrian Business Promotion Agency (SFG). The Austrian Research Promotion Agency (FFG) has been authorized for program management.

Acknowledgments: The author acknowledges the kind permission from Elsevier and Tribology Online to reproduce Figures 2, 4, 7-9 and 13 and Figures 10A,B and 11, respectively. Please note that the rights for these figures are owned by a third party and that permission for any further reuse must be obtained from the relevant holder of the exclusive rights.

Conflicts of Interest: The authors declare no conflict of interest.

\begin{tabular}{|c|c|}
\hline \multicolumn{2}{|c|}{ Abbreviations } \\
\hline \multicolumn{2}{|c|}{ The following abbreviations are used in this manuscript: } \\
\hline \multicolumn{2}{|c|}{ API American Petroleum Institute } \\
\hline \multirow{2}{*}{\multicolumn{2}{|c|}{ ASTM American Society for Testing and Materials }} \\
\hline & \\
\hline \multirow{2}{*}{$\begin{array}{l}\mathrm{RB} \\
\mathrm{PAO}\end{array}$} & Rolling bearing \\
\hline & Polyalphaolefins \\
\hline \multirow{2}{*}{$\begin{array}{l}\text { PFPE } \\
\text { PTFE }\end{array}$} & Perfluoropolyethers \\
\hline & Polytetrafluoroethylene \\
\hline \multirow{2}{*}{$\begin{array}{l}\text { SEM } \\
\text { NLGI }\end{array}$} & Scanning electron microscope \\
\hline & National Lubricating Grease Institute \\
\hline ZDDP & Zinc dithiophosphate \\
\hline
\end{tabular}

\section{References}

1. Allmaier, H.; Priestner, C.; Six, C.; Priebsch, H.; Forstner, C.; Novotny-Farkas, F. Predicting friction reliably and accurately in journal bearings-A systematic validation of simulation results with experimental measurements. Tribol. Int. 2011, 44, 1151-1160. [CrossRef]

2. Sander, D.E.; Allmaier, H.; Priebsch, H.H.; Witt, M.; Skiadas, A. Simulation of journal bearing friction in severe mixed lubricationValidation and effect of surface smoothing due to running-in. Tribol. Int. 2016, 96, 173-183. [CrossRef]

3. Sander, D.E.; Allmaier, H.; Priebsch, H.H. Friction and Wear in Automotive Journal Bearings Operating in Today's Severe Conditions; IntechOpen: London, UK, 2016.

4. Allmaier, H.; Priestner, C.; Sander, D.E.; Reich, F. Friction in Automotive Engines; IntechOpen: London, UK, 2013 ; pp. 149-184.

5. Sander, D.E.; Allmaier, H. Starting and stopping behavior of worn journal bearings. Tribol. Int. 2018, 127, 478-488. [CrossRef]

6. Allmaier, H.; Priestner, C.; Reich, F.M.; Priebsch, H.H.; Novotny-Farkas, F. Predicting friction reliably and accurately in journal bearings-Extending the EHD simulation model to TEHD. Tribol. Int. 2013, 58, 20-28. [CrossRef]

7. Allmaier, H.; Sander, D.E. Piston-Pin rotation and lubrication. Lubricants 2020, 8, 30. [CrossRef]

8. Morales-Espejel, G.E.; Lugt, P.M.; Pasaribu, H.; Cen, H. Film thickness in grease lubricated slow rotating rolling bearings. Tribol. Int. 2014, 74, 7-19. [CrossRef]

9. Cann, P. Understanding grease lubrication. Tribol. Ser. 1996, 31, 573-581.

10. Greenwood, J.A.; Tripp, J. The contact of two nominally flat rough surfaces. Proc. Inst. Mech. Eng. 1970, 185, 625-633. [CrossRef]

11. Qiu, M.; Chen, L.; Li, Y.; Yan, J. Rolling Bearing Lubrication Theory; Springer: Berlin/Heidelberg, Germany, 2017 ; pp. 145-185.

12. Rezasoltani, A.; Khonsari, M. On monitoring physical and chemical degradation and life estimation models for lubricating greases. Lubricants 2016, 4, 34. [CrossRef]

13. Williams, T.; Ribadeneira, X.; Billington, S.; Kurfess, T. Rolling element bearing diagnostics in run-to-failure lifetime testing. Mech. Syst. Signal Process. 2001, 15, 979-993. [CrossRef]

14. Ioannides, E. EHL in rolling element bearings, recent advances and the wider implications. Tribol. Ser. 1997, 32, 3-14. 
15. Lin, C.L.; Meehan, P.A. Morphological and elemental analysis of wear debris naturally formed in grease lubricated railway axle bearings. Wear 2021, 484, 203994. [CrossRef]

16. Yokoyama, F. Optimization of grease properties to prolong the life of lubricating greases. J. Phys. Sci. Appl. 2014, 4, 236-247.

17. Farcas, F.; Gafitanu, M. Some influence parameters on greases lubricated rolling contacts service life. Wear 1999, 225, 1004-1010. [CrossRef]

18. Rhee, I. Precision Bearing Grease Selection Guide; Technical Report; The Defense Technical Information Center (DTIC) Document; The Defense Technical Information Center: Fort Belvoir, VA, USA, 2006.

19. Komiya, H. Rolling Bearing Lubrication Technology Trends and RED Efforts; Technical Report; JTEKT: Kariya, Japan, 2007.

20. Fowzy, M. PFPE, A Unique Lubricant for a Unique Application; Technical Report; The Defense Technical Information Center (DTIC) Document; The Defense Technical Information Center: Fort Belvoir, VA, USA, 1998.

21. HUSK-ITT. Applications and Benefits of Perfluoropolyether (PFPE) Lubricants; Technical Report; HUSKEY Specialty Lubricants: Norco, CA, USA, 2005

22. Wittel, H.; Muhs, D.; Jannasch, D.; Voßiek, J. Roloff/Matek Maschinenelemente; Springer: Berlin/Heidelberg, Germany, 2009.

23. Lugt, P. A review on grease lubrication in rolling bearings. Tribol. Trans. 2009, 52, 470-480. [CrossRef]

24. Zhang, J.; Spikes, H. On the mechanism of ZDDP antiwear film formation. Tribol. Lett. 2016, 63, 1-15. [CrossRef]

25. Bancroft, G.; Kasrai, M.; Fuller, M.; Yin, Z.; Fyfe, K.; Tan, K.H. Mechanisms of tribochemical film formation: Stability of tribo-and thermally-generated ZDDP films. Tribol. Lett. 1997, 3, 47-51. [CrossRef]

26. Dawczyk, J.; Morgan, N.; Russo, J.; Spikes, H. Film thickness and friction of ZDDP tribofilms. Tribol. Lett. 2019, 67, 1-15. [CrossRef]

27. Stratmann, A.; Jacobs, G.; Hsu, C.J.; Gachot, C.; Burghardt, G. Antiwear tribofilm growth in rolling bearings under boundary lubrication conditions. Tribol. Int. 2017, 113, 43-49. [CrossRef]

28. Evans, R.; Nixon, H.; Darragh, C.; Howe, J.; Coffey, D. Effects of extreme pressure additive chemistry on rolling element bearing surface durability. Tribol. Int. 2007, 40, 1649-1654. [CrossRef]

29. Dresel, W.; Heckler, R. Lubricants, 8. Lubricating Greases. In Ullmann's Encyclopedia of Industrial Chemistry; John Wiley \& Sons, Inc.: Hoboken, NJ, USA, 2000.

30. Lugt, P.M. Grease Lubrication in Rolling Bearings; John Wiley \& Sons: Hoboken, NJ, USA, 2012.

31. Zhou, Y.; Bosman, R.; Lugt, P.M. An experimental study on film thickness in a rolling bearing for fresh and mechanically aged lubricating greases. Tribol. Trans. 2019, 62, 557-566. [CrossRef]

32. Cann, P.; Webster, M.; Doner, J.; Wikstrom, V.; Lugt, P. Grease degradation in R0F bearing tests. Tribol. Trans. 2007, 50, 187-197. [CrossRef]

33. Damiens, B.; Lubrecht, A.; Cann, P. Influence of Cage Clearance on Bearing Lubrication. Tribol. Trans. 2004, 47, 2-6. [CrossRef]

34. Gershuni, L.; Larson, M.; Lugt, P. Lubricant replenishment in rolling bearing contacts. Tribol. Trans. 2008, 51, 643-651. [CrossRef]

35. Cann, P.; Lubrecht, A. Bearing performance limits with grease lubrication: The interaction of bearing design, operating conditions and grease properties. J. Phys. D Appl. Phys. 2007, 40, 5446. [CrossRef]

36. Li, X.; Guo, F.; Poll, G.; Fei, Y.; Yang, P. Grease film evolution in rolling elastohydrodynamic lubrication contacts. Friction 2021, 9, 179-190. [CrossRef]

37. Zhou, Y. On the Mechanical Ageing of Lubricating Greases; University of Twente: Enschede, The Netherlands, 2018.

38. Cann, P. Grease lubrication of rolling element bearings-Role of the grease thickener. Lubr. Sci. 2007, 19, 183-196. [CrossRef]

39. Lin, Z.; Wang, Y.; Chen, Y.; Xu, Z. Experimental Study on the Influence of Thickener Type on the Reflux Characteristics of Grease under Starved Lubrication. In Proceedings of the 2021 International Conference of Optical Imaging and Measurement (ICOIM), Xi'an, China, 27-29 August 2021; pp. 305-308.

40. Lundberg, J. Grease lubrication of roller bearings in railway waggons. Part 1: Field tests and systematic evaluation to determine the optimal greases. Ind. Lubr. Tribol. 2000, 52, 36-44. [CrossRef]

41. Cann, P.; Doner, J.; Webster, M.; Wikstrom, V. Grease degradation in rolling element bearings. Tribol. Trans. 2001, 44, 399-404. [CrossRef]

42. Liang, H.; Zhang, Y.; Wang, W. Influence of the cage on the migration and distribution of lubricating oil inside a ball bearing. Friction 2021, 1-11. [CrossRef]

43. Mérieux, J.; Hurley, S.; Lubrecht, A.; Cann, P. Shear-degradation of grease and base oil availability in starved EHL lubrication Tribol. Ser. 2000, 38, 581-588.

44. Chevalier, F.; Lubrecht, A.; Cann, P.; Colin, F.; Dalmaz, G. Film thickness in starved EHL point contacts. J. Tribol. 1998, 120, 126-133. [CrossRef]

45. Hibino, S.; Hosoya, T.; Nakamura, K.; Matsuoka, K.; Nagayama, T.; Kitamura, M.; Sunohara, T. A New Grease-Pocket Shape to Extend the Service Life of Grease. Tribol. Online 2008, 3, 54-58. [CrossRef]

46. Zhou, Y.; Bosman, R.; Lugt, P.M. A master curve for the shear degradation of lubricating greases with a fibrous structure. Tribol. Trans. 2019, 62, 78-87. [CrossRef]

47. Zhou, Y.; Lugt, P.M. On the application of the mechanical aging master curve for lubricating greases to rolling bearings. Tribol. Int. 2020, 141, 105918. [CrossRef]

48. Zhou, Y.; Bosman, R.; Lugt, P.M. A model for shear degradation of lithium soap grease at ambient temperature. Tribol. Trans. 2018, 61, 61-70. [CrossRef] 
49. Lundberg, J.; Parida, A.; Söderholm, P. Running temperature and mechanical stability of grease as maintenance parameters of railway bearings. Int. J. Autom. Comput. 2010, 7, 160-166. [CrossRef]

50. Booser, R.; Khonsari, M. Grease life in ball bearings: The effect of temperatures. Tribol. Lubr. Technol. 2010, 66, 36-44.

51. Mikami, H. Development of Long Life Grease for High Speed Application 'ME-1' Grease for Motor Bearings; NTN Technical Review; NTN: Osaka, Japan, 2004; pp. 20-25.

52. Hurley, S.; Cann, P.; Spikes, H. Thermal Degradation of Greases and the Effect on Lubrication Performance; Tribology Series; Elsevier: Amsterdam, The Netherlands, 1998; Volume 34, pp. 75-83.

53. Jin, X. The effect of contamination particles on lithium grease deterioration in sealed ball bearings. Lubr. Sci. 1995, 7, 233-245. [CrossRef]

54. Ciekurs, P.V.; Rosenleib, J. Failure Progression Monitoring of Grease Lubricated Tapered Roller Bearings by Wear Debris Analysis; Technical Report; Naval Air Engineering Center, Support Equipment Engineering Department: Lakehurst, NJ, USA, 1982.

55. Franke, E.; Poll, G. Service life and lubrication conditions of different grease types in high-speed rolling bearings. Tribol. Ser. $1999,36,601-609$. 